\title{
Correction to: Diagnosis of Liver Disease
}

Etsuko Hashimoto, Paul Y. Kwo, Arief A. Suriawinata, Wilson M. S. Tsui, and Masaki Iwai

\section{Correction to: \\ E. Hashimoto et al. (eds.), Diagnosis of Liver Disease, https://doi.org/10.1007/978-981-13-6806-6}

E-mail address of Masahiko Koda was not included in the original version of the chapters 11 and 14. This has been included as “masakoda89@yahoo.co.jp" now.

The updated online version of these chapters can be found at https://doi.org/10.1007/978-981-13-6806-6_11

The updated online version of these chapters can be found at https://doi.org/10.1007/978-981-13-6806-6_14 